\title{
Assessing the Automation Potentials of Management Reporting Processes
}

Benjamin Matthies. FH Muenster - University of Applied Sciences, Germany, benjamin.matthies@fhmuenster.de

\begin{abstract}
Digitalization is driving the automation of accounting processes. It is estimated that up to $70 \%$ of administrative activities could be carried out by automated, i.e. rule-based sequences, which promises a considerable increase in productivity and efficiency for repetitive, standardized processes. In recent years, Robotic Process Automation (RPA) has been increasingly and successfully used for such purposes. However, before implementing a RPA solution, it is essential to evaluate the automation potentials. In the literature, such evaluations are based almost exclusively on process-oriented factors, such as the frequency and duration of processes or the degree of standardization. The assessment of potential cost benefits is often carried out secondarily and on the basis of cost estimates at a higher level. In order to close this gap and to make the cost-based assessment of automation potentials more soundly assessable, this article demonstrates a corresponding approach using Time-Driven ActivityBased Costing (TD ABC). For this purpose, a typical example from accounting is used for a demonstration with a management reporting process.
\end{abstract}

Keywords: management reporting, automation, RPA, time-driven activity-based costing 


\section{INTRODUCTION}

Digitalization is making great strides in accounting (Kruskopf et al., 2019). An emerging sub-area in this context is the automation of manual accounting processes (Huang \& Vasarhelyi, 2019; Rozario \& Vasarhelyi, 2018; Zhang et al., 2017). The reasons for such automation efforts lie not only in steadily increasing costs and the associated pressure to rationalize, but also in coping with a growing volume of tasks and increasing quality requirements (Alexander et al., 2018). In this respect, the automation of repetitive, administrative processes promises a substantial increase in productivity and efficiency (Cooper et al., 2019; Fernandez \& Aman, 2018; Kaya et al., 2019). This has ultimately led to more and more companies exploring their automation potential (Deloitte, 2018; Forrester Research, 2018).

For the implementation of automated processes, the solution of Robotic Process Automation (RPA) has increasingly established itself in recent years (Kaya et al., 2019; Santos et al., 2020; Syed et al., 2020). RPA can be described as "a preconfigured software instance that uses business rules and predefined activity choreography to complete the autonomous execution of a combination of processes, activities, transactions, and tasks in one or more unrelated software systems to deliver a result or service with human exception management" (IEEE Corporate Advisory Group, 2017). Put more simply, RPA stands for the partially or fully automated processing of structured use cases in companies by programs that perform repetitive, rule-based tasks while working cross-functionally and across applications. Predestined processes in accounting are, among others, payment processes, account openings, invoice processing, or corporate reporting (Cooper et al., 2019; Kaya et al., 2019), whereby standardized processes with low complexity are generally best suited. It is assumed that up to $70 \%$ of repetitive administrative activities could be implemented by such rule-based and robotcontrolled processes (Forrester Research, 2018).

RPA imitates human actions and - if programmed correctly - always exactly, many times faster, without time limits and without signs of fatigue. The advantages are therefore improved productivity, cost reduction, accuracy, transparency, and compliance of process execution as well as exact capacity planning (Santos et al., 2020, provide an overview of the potential benefits of an RPA implementation in their study). Comparatively low IT investments make the 
implementation of such automated processes also financially attractive (Lacity et al., 2015a). Accordingly, the market for RPA solutions is developing dynamically. Forester Research estimates that this market will reach a volume of $\$ 2.9$ billion in 2021 (starting from $\$ 250$ million in 2016). However, the diffusion and maturity of RPA is still in its infancy (Deloitte, 2018). Accordingly, several researchers stress that research should support the rapid development of RPA, for example by contributing objective concepts for its systematic establishment (Hofmann et al., 2020; Syed et al., 2020).

Prior to implementing a RPA solution, it is essential to evaluate the automation potentials (Lacity et al., 2015a; Santos et al., 2020; Syed et al., 2020), since setting up a robot involves a considerable project effort for process modeling and analysis as well as programming and testing. In the literature, the evaluation of such projects is based almost exclusively on process-oriented factors, such as the volume and frequency of processes, the degree of structuring and standardization, and access to the necessary data (Santos et al., 2020; Hermann et al., 2018). Nevertheless, it is not only a matter of finding the processes that are suitable in terms of process characteristics, but also those that are most suitable from an economic perspective. However, such economic evaluations are often only carried out on a lump-sum basis using high-level cost estimates (see Section 2). A more detailed cost-based assessment would not only be helpful for yes-no decisions, but also for the prioritization of such projects, so that limited resources are deployed where the most promising cost benefits are to be found. These are statements that can only be expressed to a limited extent by qualitative process factors.

The cost benefits of process automation can generally be calculated on the basis of the frequency of the process, the process runtime, the workload and the cost of the executing full-time equivalent (FTE). In short, it is a matter of calculating the 'automation value' expressed in cost savings, comparing current costs with potential cost savings and associated implementation costs. In practice, however, the exact calculation of such potentials causes difficulties. Kokina \& Blanchette (2019, p. 14) summarize corresponding findings through interviews with practitioners: „Organizations continue to experience challenges in return measures due to imperfect tracking mechanisms for hours and costs". Accordingly, Syed et al (2020) stress the need for research that provides appropriate objective procedures and metrics to guide the reasoning behind the development and 
implementation of RPA. For this reason, the use of Time-Driven Activity-Based Costing (TD $\mathrm{ABC}$ ) is predestined for the cost-oriented evaluation of process automation. Although TD ABC has been widely used and demonstrated (Dejnega, 2011; Santana \& Afonso, 2015), it has not yet been used for evaluation of RPA implementations.

Therefore, the aim of this article is to demonstrate an evaluation approach for process automation with TD ABC. A typical example from accounting is taken up with a management reporting process. The corresponding research objective (RO) can thus be summarized as:

RO: Demonstration of an approach to evaluate cost-related automation potentials of management reporting processes using TD $A B C$.

With regard to this research objective, this paper is structured as follows: Section 2 will first provide deeper insights into the automation of management reporting processes. Section 3 introduces the concept of the evaluation approach based on TD ABC. Section 4 demonstrates the use of the approach with an illustrative, simplified teaching case. Section 5 discusses the potential implications and limitations. Section 6 provides a conclusion and outlook.

\section{AUTOMATION OF MANAGEMENT REPORTING PROCESSES}

Management reporting is a central activity in management accounting and can be defined abstractly as the function of providing relevant business information to support management in making targeted decisions (Howell \& Soucy, 1988). The typified reporting process initially includes the activities of data acquisition, preparation and analysis, before the report preparation, plausibility check and commenting as well as the final report distribution are carried out. Studies show that approx. $70 \%$ of the total process effort is required for the first steps of data processing and analysis as well as for report preparation. Thus, the majority of the effort in the reporting process lies in non-value-adding activities (Langmann \& Turi, 2020). Against this background, reporting activities have a lot of potential for automation.

RPA is often stated as a solution for automating reporting processes (Moffitt et al., 2018; Alexander et al., 2018; Langmann \& Turi, 2020), whereby the full automation potential can be tapped, especially for repetitive, rule-based activities (van der Aalst et al., 2018). Standardized calculations of key performance 
indicators, which are often fed from a multitude of Enterprise Resource Planning (ERP) reports, Excel-based evaluations, and other external information sources, can be exemplary use cases of RPA, where management accounting can benefit from the high process speed and accuracy. In this context, another advantage of RPA is to automate processes that are not "end-to-end", but where manual intervention is required to bridge interfaces (Alexander et al., 2018). On the system side, this is often the case with the process-related connection of ERP systems when business processes require the integration of information into the workflows of ERP systems. The retrieval of ERP information and its preparation and integration into an analytical environment (e.g. MS Excel) is just one example. Competence- and decision-based processes, on the other hand, such as report interpretation, commenting and discussion always require human interaction and therefore cannot be replaced by RPA, but can be supported in some areas (Alexander et al., 2018).

Several examples of the implementation of RPA can be found in accounting (Cooper et al., 2019; Kaya et al., 2019). To give a few examples, the case study by Lacity et al. (2015a) can be mentioned, which describes the successful implementation of over 160 robots at Telefónica O2. Fernandez and Aman (2018) describe the successful implementation of RPA in Global Accounting Services. Anagnoste (2017) describes the implementation of robots in a finance department where transaction data had to be processed and reconciled for further analysis on a daily basis.

The examples also emphasize that automation always has an economic purpose at its core. A central question in the context of an RPA implementation is, therefore (Lacity et al., 2015a): Will the implementation be economically viable, i.e. will there be a sufficient cost advantage? This is not just a question of "yes or no", but ultimately also of prioritizing implementation alternatives according to costsaving potential. In an environment of limited resources, the processes that promise the most promising ROI should first be automated. Such an evaluation is also essential because, in addition to the operating, maintenance and licensing costs, the implementation of a robot (including process analysis, programming, test phase) accounts for a large part of the costs (Langmann \& Turi, 2020). According to surveys, the majority of implementation costs for a robot are in the range of approx. $€ 15,000$ to $€ 100,000$, while annual operating costs (maintenance, licenses, etc.) can be below $€ 10,000$ (Forrester Research, 2018). If the expected 
capacity savings are rather small (e.g. due to insufficient volume of process runtimes or frequencies), the investment is unlikely to pay off from a purely financial perspective, despite the high automation potential of using the robot.

To get an overview of the commonly applied evaluation approaches, the literature review by Osman (2019) was used as a basis, which collected renowned case studies on RPA implementation. Based on an analysis of these case studies, three methods for the cost-oriented evaluation of RPA implementations can be identified:

(a) Process evaluations based on qualitative factors (such as process frequency, duration or standardization) are commonly used to estimate costsaving potentials (Aguirre \& Rodrigez, 2017; Blue Prism 2019). One argument is that primarily scalable, repetitive and standardized processes have the potential to cover the costs of implementing, maintaining, and servicing the robots. This can be a first indication to support decision-making, in connection with the assumption that robots operate at $10-30 \%$ of the cost of an FTE (Deloitte, 2018).

(b) Another common approach to assessing cost savings is the rough ex-ante estimation or more accurate ex-post evaluation of hours saved and FTE released or re-allocated (Anagnoste, 2017; Asatiani \& Penttinen, 2016; Automation Anywhere, 2019; Kedziora \& Kivirante, 2018; Lacity et al., 2015a; Lacity et al., 2015b). In this context, Kokina \& Blanchette (2019) emphasize the practical problems of accurately estimating the time required for process activities, which in turn makes it difficult to estimate current process costs and thus potential time and cost savings from automation.

(c) A further evaluation indicator for the automation potential is the increased productivity, which can be determined based on the additional cases that can be processed and which ultimately leads to economies of scale (Ratia et al., 2018). For example, Aguirre \& Rodriguez (2017) accordingly expressed the productivity gains generated by RPAs on the basis of a $20 \%$ increase in process capacity.

Based on this review of the common evaluation procedures, a lack of detailed cost analysis can be identified. Although the majority of the available case studies provide detailed qualitative process criteria for evaluation (including process frequency, duration, complexity, and standardization; see for a detailed summary 
Santos et al., 2020), the evaluation of cost benefits, however, is more likely to be carried out subsequently and on the basis of high-level cost assessments (e.g. by estimating the release of capacity in FTE). This approach certainly provides a useful cost estimate, but it is, however, only a vague basis for decision making, given the extensive implementation costs. In this context, one of the central problems can be seen in the exact estimation of the "hours saved" (Kokina \& Blanchette, 2019). The present study addresses this problem by demonstrating TD $\mathrm{ABC}$ as an approach that provides the necessary guidance and structure for such assessments. With this method, it is possible to estimate not only the exact activity times in processes but also, based on this, exact process costs.

\section{EVALUATION APPROACH BASED ON TD ABC}

\subsection{Time-Driven Activity-Based Costing}

This article demonstrates the use of the method Time-Driven Activity-Based Costing (TD $\mathrm{ABC}$ ) for the cost-based evaluation of automation potentials. TD ABC is a method described by Kaplan \& Anderson (2004) for the detailed analysis of process costs, where the basic idea is that overhead costs should no longer be distributed to processes according to abstract overhead rates, but calculated directly according to the actual time consumption of operational resources during the execution of activities (Kaplan \& Anderson, 2007). For this purpose, two parameters are mathematically combined: (1) the cost per unit time of a resource executing the process activities and (2) the estimated time units for executing an activity. As a result of a TD ABC implementation, cost and time formulas are set up, which represent a precise description of the process, i.e. its resources, the corresponding costs, the activities to be executed and the required unit times (explained in more detail in the following Section 3.2).

$\mathrm{TD} A B C$ is predestined for the evaluation of process automation projects. TD $\mathrm{ABC}$ creates transparency about the actual cost drivers, which ultimately have to be reduced in a targeted manner through the implementation of RPA. This means that the evaluation takes place at exactly the level at which automation potentials can be assessed, which can basically be estimated on the basis of the frequency of a process, the process duration as well as the capacity used and the costs of involved resources (e.g. FTEs). Thus, the creation of a TD ABC logic contains the same analysis of the process characteristics that would have to take place anyway if an RPA implementation is to be planned, designed, and implemented. In 
addition, a deeper understanding of the process is created in this way, which can also form the basis for process optimizations. A further advantage is that TD $\mathrm{ABC}$, due to its simple logic, can generate transparent models in the form of a time-based algorithm, which, on the one hand, allow flexible simulations and, on the other hand, can be used as a template for other processes and transferred in an adapted form.

In the following Section 3.2, the conception and process of such a TD ABC model will be described in an abstract way before a demonstration will be given in Section 4 by means of a simplified case study.

\subsection{Methodical Foundations}

TD ABC mathematically combines two parameters: (1) cost per unit time of a resource executing the process activities and (2) the estimated time units for executing an activity. Mathematically, the underlying logic can be expressed (Bruggemann et al., 2005; Everaert et al., 2008) by calculating the costs of the individual events $k$ of activity $\mathrm{J}$ :

$$
J=t_{j, k} \cdot c_{i}
$$

Where:

$c_{i}=$ is the cost $c$ per unit (minute) of resource pool $i$

$t_{j, k}=$ is the time consumed by the event of activity $j, k$

By setting up a time equation, the time $\left(\mathrm{t}_{\mathrm{j}, \mathrm{k}}\right)$ consumed by the event of an activity $(j, k)$ can be expressed as a function of various combined time drivers. Bruggemann et al. (2005) formulate the following time equation, which represents the required time for an event $k$ of an activity $j$, with $p$ possible time drivers $X$, whereby $\beta 1$ indicates the increase in time for the increase by one unit in $X 1$ (when $X 2, \cdots, X p$ are held constant):

$$
t_{j, k}=\beta_{0}+\beta_{1} \cdot X_{1}+\beta_{2} \cdot X_{2}+\beta_{3} \cdot X_{3}+\ldots+\beta_{p} \cdot X_{p}
$$


Where:

$\mathrm{t}_{\mathrm{j}, \mathrm{k}}=$ time required to perform event $\mathrm{k}$ of activity $j$

$\beta_{0}=$ constant amount of time for activity $j$, independent of the characteristics of event $k$

$\beta_{1}=$ time consumption for one unit of time driver 1

$X_{1}=$ time driver $1, X_{2}=$ time driver $2, \ldots, X_{P}=$ time driver $p$,

$P=$ the number of time drivers that determine the time needed to perform activity $j$

The total process costs can thus ultimately be represented as (Siguenza-Guzman et al., 2014):

\section{Total Cost of a Process $=\sum$ Costs of Indiviual Activities}

The TD ABC implementation described in this article can be illustrated by means of a process with the levels 0 and A, B, C described below (based on Bruggmann et al., 2005; Kaplan \& Anderson, 2004) (Figure 1).

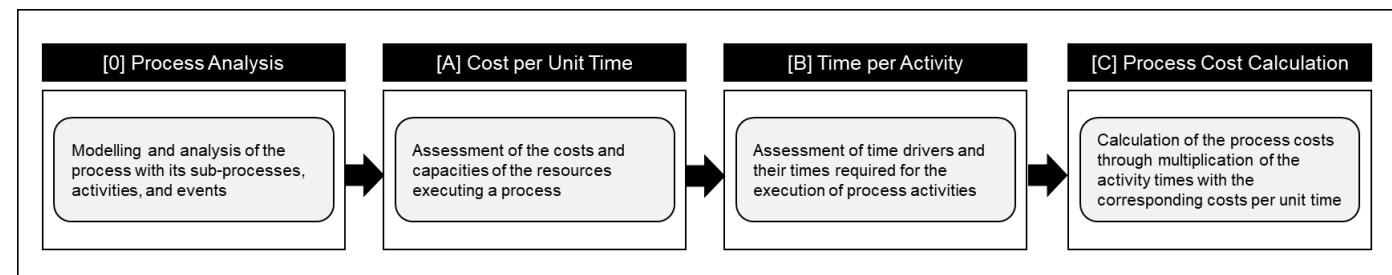

Figure 1. TD ABC process

0. The implementation is initially preceded by an understanding of the process. This includes an abstract process modeling with its sub-processes and activities. This usually includes a process analysis and optimization of potential weak points.

Based on this, the implementation of TD ABC includes the calculation levels A, $\mathrm{B}$, and $\mathrm{C}$ with corresponding work steps (Bruggemann et al., 2005; Dejnega, 2011):

A. Evaluate the costs and capacities of the resources executing a process

1. Identification of the resources carrying out the process and its activities

2. Determining the costs of these resources

3. Determination of the available capacities of resources 
4. Calculating the cost of the resources by dividing their total cost by their available time capacity

B. Assessment of unit times required for the execution of the process activities

1. Identification of the relevant time drivers, i.e. the factors to be considered when carrying out the relevant activities

2. Estimate of the times associated with the time drivers per activity

3. Setting up the time equation, which describes all time drivers and their time consumption during the execution of an activity

C. Calculation of the process costs by multiplying the activity times by the corresponding resource costs

The practical implementation of the $\mathrm{TD} A B C$ method is demonstrated in the following Section 4 using the exemplary evaluation of a reporting process.

\section{DEMONSTRATION}

\subsection{Case Description}

The following demonstrative case study describes the cost assessment of an exemplary automation of a typical management reporting process. The aim is to evaluate the economic benefit by calculating potential cost savings as accurately as possible. The procedure is structured as follows: In the first step, process models of the actual 'as-is' state (manual process execution by a management accountant) as well as the target 'to-be' state (automated process execution using RPA) are described in Section 4.2. Based on this, a comparative cost analysis is carried out using the TD ABC method, whereby the analysis process described in Section 3 is applied for the actual state and the target state (see Sections 4.3 - 4.5). Finally, the cost advantages of the automation project are evaluated (Section 4.6).

\subsection{Process Modeling and Analysis}

Process modeling is a means of overcoming the complexity problem of understanding practical procedures (Becker et al., 2000). This includes structuring the process model into sub-processes and detailed activities. In this regard, the modeling of the actual state ('as-is') of the process is the basis for the identification of weaknesses and the localization of improvement potentials. Based on the weakpoint analysis resulting from the as-is modeling, the 'to-be' state can be modeled. 
The demonstrative process describes the typical procedure of a management reporting (see Figure 2). Management reporting can be described as the means and activities of a company to develop, distribute and store the business information relevant to the decision-making of the management (Howell \& Soucy, 1988). This example describes a twice-weekly sales reporting, in which typical sales information (including net sales, margins, pricing information, time comparisons and target/actual comparisons) is prepared for various target groups (business units, regional management, operational control units, sales staff). The structured modeling of this reporting process is based on typical sub-processes (Leßweng, 2004): (1) data acquisition, processing and analysis; (2) report preparation; (3) report distribution; and (4) report management. The 'as-is' process (process execution by a management accountant) is to be described on the basis of these sub-processes and corresponding activities, before the optimization of the 'to-be' process (process execution partly by RPA) is described.

\section{(1) Data acquisition, processing and analysis}

The process starts with the data collection activities on fixed dates (triggering event). Three different data (csv format) from different sources are queried: (1a.) sales data from an ERP system; (1b.) customer data (including master data and classifications) from a Customer Relationship Management (CRM) system; (1c.) planning data from a separate MS Access database. After querying the data, the downloaded documents are named and stored in a predefined folder. In the next step, this data is manually converted into an Excel file and formatted uniformly for merging (2a.-c.). The transformed data is then transferred into analytical templates (MS Access database and Excel file) (3.) and various key performance indicators (including relations, time and target/actual comparisons) are calculated (4.).

\section{(2) Report preparation}

The created database is used in the following sub-process to update predefined visualizations and tables in a MS PowerPoint format in order to create the actual report (5.). The management accountant then performs a check, makes corrections (e.g. additions and formatting if necessary) and adds comments (6.). Finally, a report document is generated in PDF format (7.). 


\section{(3) Report distribution}

On the one hand, the report document is stored in a predefined archive (8.) and on the other hand, it is sent by e-mail to a defined group of people (9.).

\section{(4) Report management}

Subsequently, the management accountant is available for maintenance of the report, i.e. further correction, extension or discussion if necessary (10.).
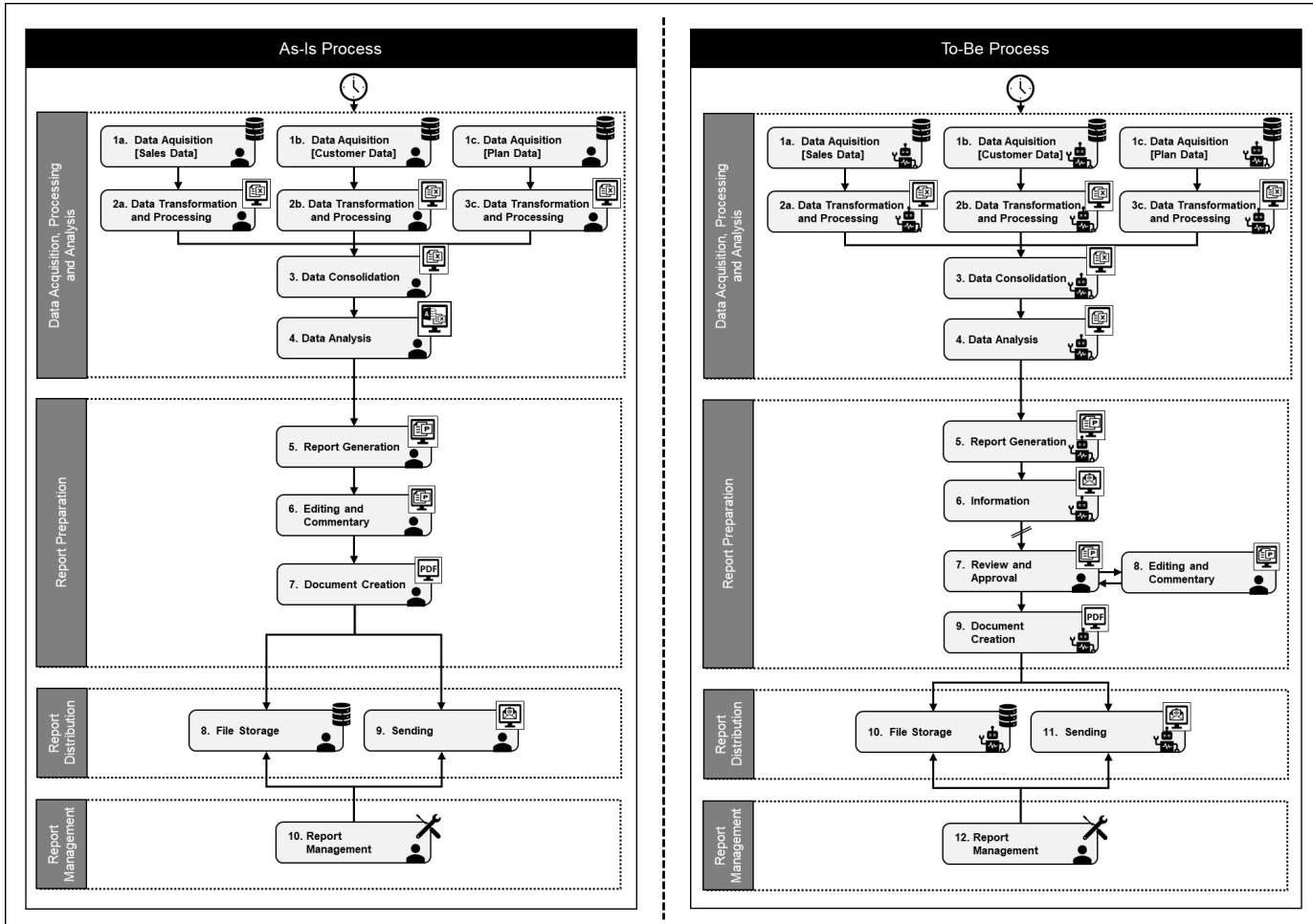

Figure 2. Exemplary management reporting process (as-is vs. to-be)

The 'to-be' process describes the potential for automation through RPAs that is to be evaluated. The described reporting consists to a large extent of data acquisition and preparation as well as report generation. In particular, the export of data from various sources, their reformatting, integration into Excel, among others, and the standardized calculation and visualization of key figures represent repetitive, standardized tasks. Such tasks are predestined for automation. In contrast, RPA can also be used to overcome system interfaces, such as between ERP and MS Office applications. Such activities can be fully automated and then executed autonomously. 
In the 'to-be' process, a large part of the standardizable, i.e. rule-based activities can be performed by a programmed robot (1.-6.; 9.-11.), whereby the robot works from its own virtual workstation (with its own ID and access rights), comparable to those of a human worker. The individual steps of the activities are programmed using rule-based, orchestrated sequences (example 1a.: open ERP system > perform login $>$ execute predefined transaction $>$ enter current parameters (date, organizational unit, etc.) $>$ execute data query $>$ download, name and save the file in a predefined folder). Activity (6.) is new and involves the robot sending an email information to the responsible management accountant after the initial creation of the report, who then (7.) performs a review and approval of the automatically generated report and performs the (8.) editing and commenting. After approval, the robot takes over again and (9.) creates and (10./11.) sends/saves the report. This means that cognitive work and decisions (interpretations, evaluations, comments) remain the responsibility of the human. As well as individual rework within the scope of report management (12.).

\subsection{Cost of Resources}

$\mathrm{TD} \mathrm{ABC}$ is a model that allocates resource costs to process activities according to their time capacity. The costs of all required resources (personnel, machines, etc.) are divided by the available (time) capacities, whereby this capacity is the time of the work that can actually be performed (Kaplan \& Anderson, 2004). As a result, the costs per unit time are calculated. The mathematical expression is thus (Bruggemann et al., 2005):

$$
\text { Cost per Unit Time }=\frac{\text { Time Cost of the Resource }}{\text { Available Capacity }}
$$

The corresponding resource costs for (a) the 'as-is' process and (b) the 'to-be' process are calculated below.

\section{(a) As-is process}

The resource executing the 'as-is' process is primarily the respective management accountant. For the purpose of this simplified teaching case, the annual personnel costs for this employee are estimated at $€ 80,000$. In addition, other costs, such as material costs or workstation costs, should be covered by a simplified overhead rate of $20 \%$ of the personnel costs. 
The time capacity of the management accountant is expressed for costing purposes as the practically available working minutes per year. Assuming an annual working time of 42 weeks (40 hours each), this results in a potential time capacity of 1,680 hours (= 100,800 minutes). The actual, practically realistic capacity is often assumed to be approximately $80 \%$ of the theoretical full-time capacity (Kaplan \& Anderson, 2004). This results in a reduced potential time capacity of 80,640 minutes.

Cost Category

Cost $(€)$ per Year

Capacity (min.) per Year

Personnel Costs

80,000

Overhead Costs

16,000

80,640

Total

96,000

80,640

Table 1. Costs and Capacity of a Management Accountant

Cost per Unit Time $=\frac{96.000}{80.640}=1.19$

The final cost per time unit is $€ 1.19$ per minute.

\section{(b) To-be process}

Generally speaking, the costs of a robot can be estimated to be about $10 \%$ of a corresponding employee (of an industrialized country) (Deloitte, 2018). In order to estimate the level of capacity savings at which the use of robots appears reasonable, the implementation costs need to be assessed as well as the ongoing operating costs of the selected RPA solution. Studies confirm that the majority of the implementation costs for a robot (process analysis, design, programming, testing, etc.) range from approx. $€ 15,000$ to over $€ 100,000$, whereas the annual operating costs (maintenance, licenses etc.) can often be less than $€ 10,000$ (see the detailed results on cost distribution in Forrester Research, 2018, p. 7). Another strength of an RPA implementation is that comparatively little or no technical adjustments to the IT infrastructure and IT investments are required. RPA involves the implementation of a software-based executing activity in existing 
infrastructures, only that this activity is performed by robot-controlled automatisms instead of by humans.

The one-time costs of implementing a robot depend strongly on the individual company, such as its size, but also its digitalization maturity and the situation whether RPA is already in use (Langmann \& Turi, 2020). One-time costs of implementation are incurred in particular for consulting, conception, evaluation, planning, design and programming, deployment and initial training, and testing. Since this reporting process is a comparatively simple use case, a minimum lumpsum of $€ 15,000$ is assumed for the implementation costs, which still corresponds to the study results of Forrester (Forrester Research, 2018), although in practice there is a wide range of costs from $€ 15,000$ to over $€ 100,000$.

In summary, ongoing operating costs consist of several components such as software license costs, costs for storage and virtual workstation, robot maintenance, infrastructure maintenance. In addition, it should be emphasized once again that the necessary investments and ongoing operating costs for RPA depend strongly on the respective provider, the chosen licensing model, and the existing know-how in the organization (Langmann \& Turi, 2020). For the purpose of this simplified teaching case, a lump-sum of $€ 10,000$ should be budgeted for this cost pool (Forrester Research, 2018). These operating costs also take into account the fact that the robot would have to be adjusted to new data processing or report content during operation. In this case, since it is also assumed that the robot is not the only robot in use in the organization, only portions of overhead costs, such as infrastructure or RPA platform costs, are considered. As a result, these figures also correspond approximately to the usual study findings, according to which a robot accounts for around 10\% of an employee's running costs (Deloitte, 2018; Forrester Research, 2018).

Theoretically, a robot is available all day (24/7), although it is also dependent on the availability of the IT infrastructure. In this calculation, therefore, the annual availability of the IT infrastructure (in hours and minutes) with a downtime of $10 \%$ should be taken as a basis. This results in a potential time availability of the RPA capacity of 7,884 hours (=473,040 minutes). Of course, the use of the robot is limited by the maximum number and scope of the processes to be carried out, but the entire capacity actually available should be taken as a basis here. 
As a result, the following costs and time capacities are calculated (see Table 2), whereby it should be noted that the implementation costs as a one-off effect are not included in the calculation of the cost per unit time, but only the annual operating costs. However, the implementation costs are included in the final evaluation of cost benefits in the sense of an amortization (payoff) calculation.

Cost Category

Cost $(€)$ per Year

Capacity (min.) per Year

Implementation Costs

15,000

Operating and Maintenance Costs

10,000

473,040

Total (excl. Implementation Costs)

10,000

473,040

Table 2. Costs and Capacity of a Robot

Cost per Unit Time $=\frac{10.000}{473.040}=0.02$

The final cost per unit time is $€ 0.02$ per minute.

\subsection{Times of Activities}

After calculating the cost per unit time for the provision of resources dedicated to the reporting activities, the next step is to calculate the time required to perform each activity. According to the logic of TD ABC, the process time is the sum of the individual activity times. Since a process has a defined start and end event (start: initialization of the data acquisition; end: report is saved and sent), the process time in between can be measured, whereby these figures can be determined by robust estimates (Kaplan \& Anderson, 2004). In the case of our example, it is assumed that a management accountant needs on average 15 minutes to query the first data set (including the steps: logging into the system, opening the transaction, entering the query parameters, downloading and saving the data as a csv file in a pre-defined folder with a pre-defined notation).

In this example, the process execution is dependent on the report to be created, since the creation of a predefined, standardized report is the exclusive focus of this example. If several reports with varying content were required in this 
example, the number of reports would be the factor that would increase the process frequency and therefore the number of activities to be executed. Furthermore, the process does not have any contingencies or conditions (in the sense of an "if" function), since the report is created according to a precisely defined pattern. If this pattern cannot be executed (e.g. a data query is not available at the corresponding time), the process would be aborted and a message would be generated.

The roughly estimated times of the 'as-is' and 'to-be' process are as shown in Table 3. In the 'as-is' process, the activities of data acquisition, processing and analysis, in particular, generate the greatest time expenditure ( 98 minutes in total). The subprocesses of report preparation (49 minutes) and report distribution (10 minutes) have comparatively shorter times. In particular, the activity of (6./8.) editing and commentary (35 minutes) represents an average estimate, which may vary depending on the case. The sub-process of report management (10./12.) is excluded from the analysis, as this is a subsequent and case-dependent and therefore non-standardized activity that cannot be automated.

The 'to-be' process represents the time units consumed by the robot for process execution, which are much faster due to computer-based execution. The process starts automatically at a pre-defined time. The process has two additional activities that imply a break in process execution. After the initial report generation (5.), the bot sends information to the management accountant (6.), who then carries out an evaluation (7.) and the subsequent editing and commenting (8.), before the approval (7.) for the continuation of the automated process (by manually re-activating the robot) takes place. 


\begin{tabular}{|c|c|c|c|c|c|}
\hline \multirow[t]{2}{*}{ Sub-Process } & \multirow[t]{2}{*}{ Activity } & \multicolumn{2}{|c|}{ As-Is Process } & \multicolumn{2}{|c|}{ To-Be Process } \\
\hline & & $\begin{array}{l}\text { Time per } \\
\text { Activity } \\
\text { [min] }\end{array}$ & $\begin{array}{c}\text { Time per } \\
\text { Sub- } \\
\text { Process } \\
\text { [min] }\end{array}$ & $\begin{array}{c}\text { Time } \\
\text { per } \\
\text { Activity } \\
{[\mathrm{min}]}\end{array}$ & $\begin{array}{c}\text { Time per } \\
\text { Sub- } \\
\text { Process } \\
\text { [min] }\end{array}$ \\
\hline Data Acquisition, & 1a. Data Acquisition (Sales Data) & 8 & \multirow{8}{*}{98} & 4 & \multirow{8}{*}{38} \\
\hline Processing, and & 1b. Data Acquisition (Customer Data) & 8 & & 4 & \\
\hline \multirow[t]{6}{*}{ Analysis } & 1c. Data Acquisition (Plan Data) & 5 & & 2 & \\
\hline & 2a. Data Transformation \& Processing & 18 & & 6 & \\
\hline & 2b. Data Transformation \& Processing & 15 & & 6 & \\
\hline & 2c. Data Transformation \& Processing & 6 & & 2 & \\
\hline & 3. Data Consolidation & 20 & & 6 & \\
\hline & 4. Data Analysis & 18 & & 8 & \\
\hline \multirow[t]{5}{*}{ Report Preparation } & 5. Report Generation & 12 & \multirow{5}{*}{49} & 4 & \multirow{5}{*}{46} \\
\hline & 6. Information & - & & 1 & \\
\hline & 7. Review and Approval & - & & 5 & \\
\hline & 6./8. Editing and Commentary & 35 & & 35 & \\
\hline & 7./9. Document Creation & 2 & & 1 & \\
\hline \multirow[t]{2}{*}{ Report Distribution } & 8./10. File Storage & 4 & \multirow{2}{*}{10} & 1 & \multirow{2}{*}{2} \\
\hline & 9./11. Sending & 6 & & 1 & \\
\hline Report Management & 10./12. Report Management & - & - & - & - \\
\hline Total & & 157 & 157 & 86 & 86 \\
\hline
\end{tabular}

Table 3. Required Times per Activity and Sub-Process (as-is and to-be process)

\subsection{Process Cost Calculation}

Using the estimated times per activity and the cost per unit time of the resources, the activity costs can be calculated by multiplying the cost per unit time of the resources by the estimated time needed to carry out the activity (SiguenzaGuzman et al., 2014):

\section{Cost per Activity = Cost per Unit Time $\cdot$ Time Required to Perform an Activity}

In the logic of $\mathrm{TD} A B C$, the total process costs can then be expressed as the sum of the costs of the individual activities (Siguenza-Guzman et al., 2014). Expressed mathematically: 


$$
\text { Total Cost of a Process }=\sum \text { Costs of Indiviual Activities }
$$

Accordingly, the activity, sub-process and total process costs for the two processes under consideration (as-is and to-be) can be calculated (see Table 4).

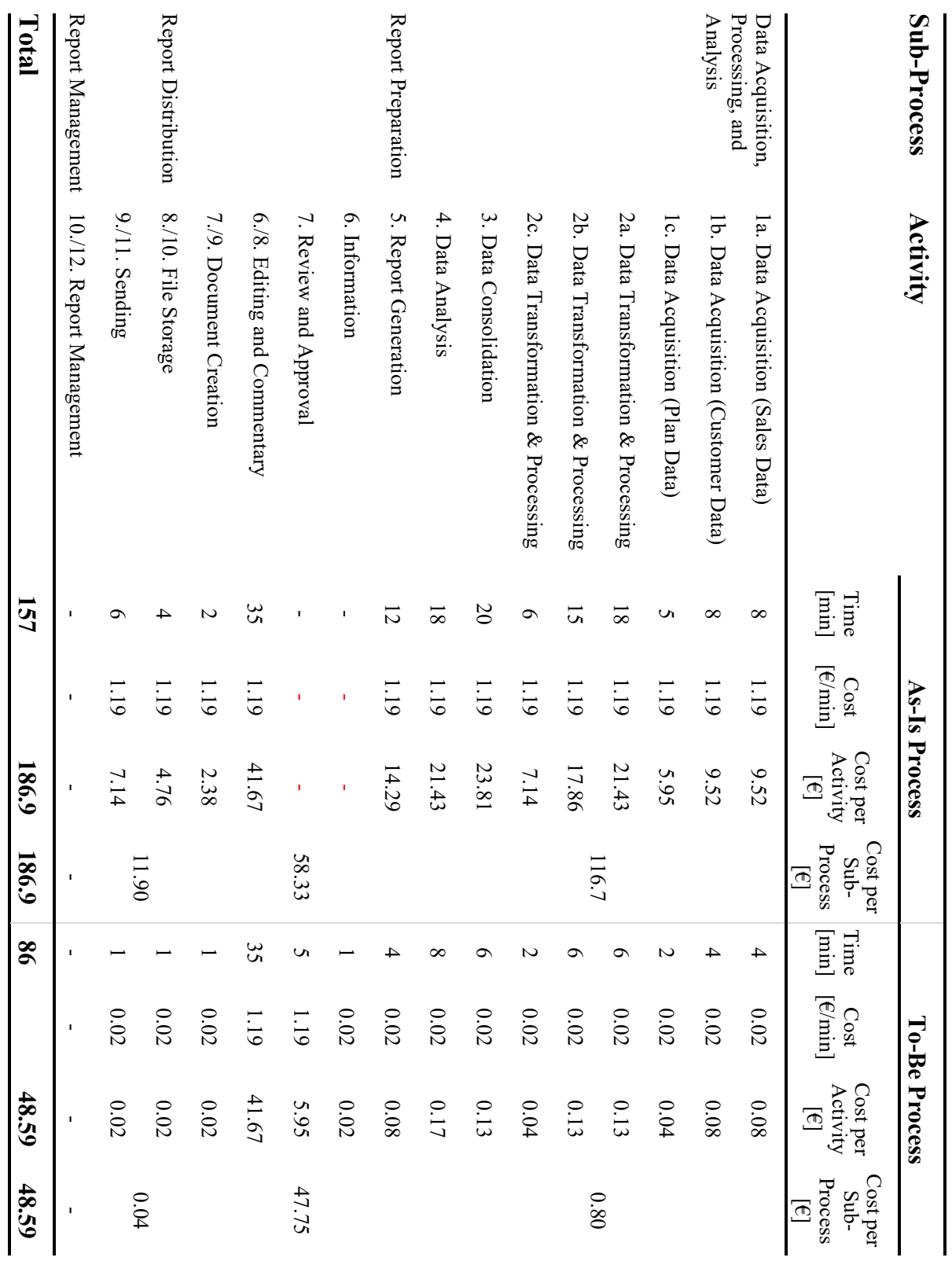

Table 4. Process Cost Calculation (as-is and to-be process) 


\subsection{Results}

As expected, the process costs of the automated 'to-be' process (€48.59) are significantly lower than those of the manual as-is process $(€ 186.90)$. On the one hand, the significantly lower costs per unit time and on the other hand, the significantly shorter activity times contribute to this, so that ultimately, the subprocess of data acquisition, processing, and analysis in particular offers the most significant savings potential (see Table 4). As a result, the cost-saving potential per process run is $€ 138.31$.

Finally, the final economic benefit of the RPA implementation will be determined, whereby the initial implementation costs for the robot must also be taken into account in this analysis. If the expected capacity savings are not sufficient to cover the initial implementation costs in the near to medium term despite the high automation value of the robot, the investment is likely to be less profitable from a purely financial point of view. This means that especially the process frequency (i.e. the frequency of report preparation) must be considered in the evaluation. In principle, the cost advantage increases with the frequency and volume of the use cases to be automated (Deloitte, 2018). Therefore, the evaluation involves an amortization calculation in the sense of a break-even point, whereby the implementation costs are divided by the cost-saving potential per process run, resulting in the required number of process runs. The mathematical expression is thus:

$$
\text { Break-Even Point }=\frac{\text { Implementation Costs }}{(\text { Process Costs As }-I s-\text { Procoess Costs To }-B e)}
$$

When applying this calculation logic, the result is a required number of process runs of $\approx 109(=15,000.00 / 138.31)$, with which the investment in automation would be covered by the respective cost savings. Against the background of a twice-weekly report generation, this point would thus be reached after a little more than a year. This information should not be lost sight of when evaluating costs and comparing automation alternatives.

In summary, the findings, the cost-saving potentials on the one hand and the determination of the amortization of the implementation costs on the other hand, make the cost-based evaluation of automation projects more soundly assessable. Especially the break-even point can be helpful in order not to lose sight of the 
implementation costs despite the cost advantages of automation, but rather to focus on the amortization of the projects for the evaluation and comparison.

\section{DISCUSSION}

As shown in Section 2, common cost assessments for automation projects are based on (a) the evaluation of qualitative processes, (b) rough preliminary estimates or ex-post assessments of cost savings from released FTE or (c) measurement of productivity gains from additionally processed cases. Although it is regularly emphasized to implement the most accurate evaluation and monitoring possible (Syed et al., 2020), the approaches used so far are thus based more on rough evaluation procedures. The demonstrated evaluation approach using $\mathrm{TD} \mathrm{ABC}$ therefore provides a more detailed solution for the cost-related evaluation of corresponding process automation projects. TD ABC is predestined for the evaluation of potential process automations because it creates a detailed time and cost transparency on a very detailed level on individual activities. In addition to the determination of pure cost savings, the focus is also on an amortization calculation. This closes a gap in the literature on RPA, since commonly used evaluation approaches primarily aim at assessing the suitability of processes in terms of process characteristics (including process frequency, duration, and standardization), but only deal with the assessment of cost benefits secondarily - and then roughly on higher-level cost estimates. The potential implications and limitations of the proposed approach will be described in more detail in the following sections.

Nevertheless, although cost reduction is a predominant goal in the optimization of operational efficiency (Syed et al., 2020), it should also be emphasized that RPA implementation does not necessarily need to have headcount and cost reduction as its primary objective, and that cost-oriented indicators are not necessarily the only or most important indicator for assessing the contribution of RPA (Hofmann et al., 2020). Kokina \& Blanchette (2019) identified a variety of measures used, such as hours given back to customers, reduced error rates, and bot efficiency (Ratia et al., 2018).

\subsection{Implications for Practice}

The proposed TD ABC approach can provide five potential implications for practice. First, the fundamental cost advantage of an intended automation project 
can be evaluated in monetary terms, whereby the results are calculated at the granular activity level. Besides fundamental decision support for or against the project, these quantitative results can also be used for the prioritization of several competing automation alternatives. Furthermore, with the amortization calculation, an evaluation measure that has not been considered in the literature so far is proposed for this purpose, which determines the break-even point for a process frequency achieving the cost advantage. As Syed et al (2020) stress the need for new, targeted metrics for the assessment of RPA benefits, this amortization measure can make a corresponding contribution. Second, the approach generates a detailed understanding of processes and activities, which can thus also be the basis for process optimization. Third, since TD ABC expresses the cost behavior of processes in a simple algorithm, a model set up in this way is also suitable for the simulation of alternative scenarios. Fourth, the cost transparency created also provides a basis for time- and cost-based benchmarking in order to compare comparable processes across organizations and identify optimization potential. Fifth, the corresponding documentation of the actual and target process forms a basis for subsequent tracking following an implemented automation solution.

The execution of a TD $\mathrm{ABC}$ analysis is of course associated with effort (especially process modeling as well as data collection and analysis). However, such a content-related understanding of the processes would have to be created anyway when dealing with the processes for their automation.

\subsection{Implications for Research}

The rapid pace of practical developments increasingly implies the need for support from research (Hofmann et al., 2020; Syed et al., 2020). There is a lack of objective procedures and metrics that guide the reasoning behind the development and implementation of RPA (Syed et al., 2020). In this context, and with special attention to the evaluation of the cost advantages of process automation, continuing research ideas can be derived (Moffitt et al., 2018). On the one hand, further concepts of cost accounting could be examined and demonstrated for their suitability. The concept of Total Cost of Ownership (TCO; Ellram, 1993) is only one idea here when it comes to evaluating the total life cycle costs of a RPA solution. On the other hand, the future development stages of RPA offer a promising potential for further evaluation questions of RPA in accounting. In this 
context, a development that will certainly drive the spread of RPA is the integration of artificial intelligence (Hofmann et al., 2020). Interesting questions arise for the evaluation and steering of intelligent robots, which can develop independently on the basis of the collected data and even develop new robots.

\subsection{Limitations}

This contribution is not free of potential limitations. In this article, only a simplified, demonstrative teaching case of the evaluation of a reporting process is presented. Thus, the contents cannot claim to be generally valid in the empirical sense. Instead, the focus is on demonstrating the evaluation approach. This, in turn, leads to the demand of further, ideally practice-oriented case studies. Furthermore, the considered context of a reporting process is only conditionally transferable to other use cases in accounting. Each reporting process is different and has individual characteristics (for example, in the context of data processing, report creation or distribution). However, the delivered proposal could serve as an adaptable evaluation template for other reporting processes.

\section{CONCLUSIONS AND OUTLOOK}

Studies show that the maturity of RPA implementations are still in their infancy in many organizations (Deloitte, 2018; Forrester Research, 2018). It can, therefore, be assumed that process automation in accounting still has an exciting future ahead of it. Moffitt et al. (2018) outline promising research questions in this regard. The evaluation of the associated cost advantages will therefore become increasingly relevant and offers some promising research perspectives in accounting. A sound understanding and control of costs, to which TD ABC contributes, is a basis for the establishment of "Robotic Operating Models" (Kokina \& Blanchette, 2019). An expert role in this field will certainly open up new career opportunities for accounting professionals, as knowledge about the management of automation processes becomes increasingly relevant. (Cooper et al., 2019). 


\section{REFERENCES}

Aguirre, S., \& Rodriguez, A. (2017). Automation of a business process using robotic process automation (rpa): A case study. In Workshop on Engineering Applications (pp. 65-71). Springer. https://doi.org/10.1007/978-3-319-66963-2_7

Alexander, S., Haisermann, A., Schabicki, T., \& Frank, S. (2018). Robotic Process Automation (RPA) im Rechnungswesen und Controlling - welche Chancen ergeben sich? Controlling, 30(3), 11-19. https://doi.org/10.15358/09350381-2018-3-11

Anagnoste, S. (2017). Robotic Automation Process - The next major revolution in terms of back office operations improvement. Proceedings of the International Conference on Business Excellence, 11(1), 676-686. https://doi.org/ 10.1515/picbe-2017-0072

Asatiani, A., \& Penttinen, E. (2016). Turning robotic process automation into commercial success-Case OpusCapita. Journal of Information Technology Teaching Cases, 6(2), 67-74. https://doi.org/10.1057/jittc.2016.5

Automation Anywhere (2019). Australia Post Optimizes Accounting Workflows with RPA Bots. Retrieved (04.06.2020) from https://www.automationanywhere. com/casestudy-australia.

Becker, J., Rosemann, M., \& Von Uthmann, C. (2000). Guidelines of business process modeling. In Business Process Management (pp. 30-49). Springer, Berlin, Heidelberg. https://doi.org/10.1007/3-540-45594-9_3

Blue Prism (2019). Coca-Cola Extends Business Services Capacity and Improves Performance with RPA. Retrieved (04.06.2020) from https://www.blueprism.com /uploads/resources/case-studies/blue-prism-cola-case-study.pdf.

Bruggeman, W., Everaert, P., Anderson, S., \& Levant, Y. (2005). Modeling logistics costs using Time-Driven ABC: a case in a distribution company. Conceptual Paper and Case Study.

Cooper, L. A., Holderness Jr, D. K., Sorensen, T. L., \& Wood, D. A. (2019). Robotic Process Automation in Public Accounting. Accounting Horizons, 33(4), S. 15-35. https://doi.org/10.2139/ssrn.3193222

Dejnega, O. (2011). Method time driven activity based costing - literature review. Journal of Applied Economic Sciences (JAES), 6(15), 9-15. 
Deloitte (2018). Deloitte Global RPA Survey. https://www2.deloitte .com/bg/en/pages/technology/articles/deloitte-global-rpa-survey-2018.html Accessed 1 April 2020.

Ellram, L. (1993). Total Cost of Ownership: elements and implementation. International Journal of Purchasing and Materials Management, 29(3), 2-11. https://doi.org/10.1111/j.1745-493x.1993.tb00013.x

Everaert, P., Bruggeman, W., \& Creus, G. de (2008). Sanac Inc.: From ABC to time-driven ABC (TDABC) - An instructional case. Journal of Accounting Education, 26(3), 118-154. https://doi.org/10.1016/j.jaccedu.2008.03.001

Fernandez, D. \& Aman, A. (2018). Impacts of Robotic Process Automation on Global Accounting Services. Asian Journal of Accounting and Governance, 9, 123-131. https://doi.org/10.17576/ajag-2018-09-11

Forrester Research (2018) Harness RPA To Optimize Customer Outcomes. https://dfe.org.pl/wp-content/uploads/2018/12/Forrester_Harness-RPA.pdf Accessed 15 March 2020.

Hermann, K., Stoi, R., \& Wolf, B. (2018). Robotic Process Automation im Finance \& Controlling der MANN+ HUMMEL Gruppe. Controlling, 30(3), 2834. https://doi.org/10.15358/0935-0381-2018-3-28

Hofmann, P., Samp, C., \& Urbach, N. (2020). Robotic process automation. Electronic Markets, 30(1), S. 99-106. https://doi.org/10.1007/s12525-019-003658

Howell, R. A., \& Soucy, S. R. (1988). Management reporting. Strategic Finance, 69(8), 22.

Huang, F., \& Vasarhelyi, M. A. (2019). Applying robotic process automation (RPA) in auditing: A framework. International Journal of Accounting Information Systems, 35, 100433. https://doi.org/10.1016/j.accinf.2019.100433

IEEE Corporate Advisory Group (2017). IEEE Guide for Terms and Concepts in Intelligent Process Automation. New York, NY: IEEE. https://doi.org/10.1109/ ieeestd.2017.8070671

Kaplan, R. S., \& Anderson, S. R. (2007). Time-Driven Activity-Based Costing: A Simpler and More Powerful Path to Higher Profits. Harvard business press. 
Kaplan, R. S., \& Anderson, S. R. (2004), Time-Driven Activity-Based Costing. Harvard Business Review, November, 131-138. https://doi.org/10.2139/ ssrn. 485443

Kaya, C. T., Turkyilmaz, M., \& Birol, B. (2019). Impact of RPA Technologies on Accounting Systems. Journal of Accounting \& Finance, 82, 235-250.

Kedziora, D., \& Kivirante, H. (2018). Digital Business Value Creation with Robotic Process Automation (rpa) in Northern and Central Europe. Management, 13(2), 161-174. https://doi.org/10.26493/1854-4231.13.161-174

Kokina, J., \& Blanchette, S. (2019). Early evidence of digital labor in accounting: Innovation with Robotic Process Automation. International Journal of Accounting Information Systems, 35, 100431. https://doi.org/10.1016/ j.accinf.2019.100431

Kruskopf, S., Lobbas, C., Meinander, H., Söderling, K., Martikainen, M., \& Lehner, O. (2019). Digital Accounting: Opportunities, Threats and the Human Factor. ACRN Oxford Journal of Finance and Risk Perspectives, 8, 1-15.

Lacity, M., Willcocks, L., \& Craig, A. (2015a). Robotic Process Automation at Telefónica O2. MIS Quarterly Executive, 15(1), Article 4.

Lacity, M., Willcocks, L., \& Craig, A. (2015b). Robotic Process Automation at Xchanging. The Outsourcing Unit Working Research Paper Series (15/03).

Langmann, C., \& Turi, D. (2020). Robotic Process Automation (RPA) Digitalisierung und Automatisierung von Prozessen. Springer Fachmedien Wiesbaden. https://doi.org/10.1007/978-3-658-28299-8

Leßweng, H.-P. (2004). Einsatz von Business Intelligence Tools (BIT) im betrieblichen Berichtswesen. Controlling, 16(1), 41-50. https://doi.org/ 10.15358/0935-0381-2004-1-41

Moffitt, K. C., Rozario, A. M., \& Vasarhelyi, M. A. (2018). Robotic process automation for auditing. Journal of Emerging Technologies in Accounting, 15(1), 1-10. https://doi.org/10.2308/jeta-10589

Osman, C. C. (2019). Robotic Process Automation: Lessons Learned from Case Studies. Informatica Economica, 23(4), 66-75. https://doi.org/10.12948/ issn14531305/23.4.2019.06 
Ratia, M., Myllärniemi, J., \& Helander, N. (2018). Robotic Process Automation Creating Value by Digitalizing Work in the Private Healthcare? In: Proceedings of the 22nd International Academic Mindtrek Conference. New York, USA: ACM Press, 222-227.

Rozario, A. M., \& Vasarhelyi, M. A. (2018). How robotic process automation is transforming accounting and auditing. The CPA Journal, 88(6), 46-49.

Santana, A., \& Afonso, P. (2015). Analysis of Studies on Time-Driven Activity Based Costing (TDABC). The International Journal of Management Science and Information Technology (IJMSIT), 15, 133-157.

Santos, F., Pereira, R., \& Vasconcelos, J. B. (2020). Toward robotic process automation implementation: an end-to-end perspective. Business Process Management Journal, 26(2), 405-420. https://doi.org/10.1108/bpmj-12-20180380

Siguenza-Guzman, L., van den Abbeele, A., \& Cattrysse, D. (2014). Time-Driven Activity-Based Costing Systems for Cataloguing Processes: A Case Study. Liber Quarterly: The Journal of European Research Libraries, 23(3), 160-186.

Syed, R., Suriadi, S., Adams, M., Bandara, W., Leemans, S. J., Ouyang, C., ter Hofstede, H.M., van de Weerd, I., Wynn, M.T., \& Reijers, H. A. (2020). Robotic Process Automation: Contemporary themes and challenges. Computers in Industry, 115, 103162. https://doi.org/10.1016/j.compind.2019.103162

van der Aalst, W. M. P., Bichler, M., \& Heinzl, A. (2018). Robotic Process Automation. Business \& Information Systems Engineering, 60(4), 269-272. https://doi.org/10.1007/s12599-018-0542-4

Zhang, L., Pei, D., \& Vasarhelyi, M. A. (2017). Toward a new business reporting model. Journal of Emerging Technologies in Accounting, 14(2), 1-15. https://doi.org/10.2308/jeta-10570 